\title{
Regional Stability Analysis of Red Clay Slope Based on Different Failure Modes: A Case Study in Taizaifu Area, Fukuoka
}

\author{
Fang Wei \\ School of Traffic and Transportation Engineering, Changsha University of Science and Technology, Changsha, \\ Hunan 410004, China \\ Correspondence should be addressed to Fang Wei; fangwei5642366@163.com
}

Received 3 July 2019; Revised 31 August 2019; Accepted 21 September 2019; Published 15 October 2019

Academic Editor: Castorina S. Vieira

Copyright (c) 2019 Fang Wei. This is an open access article distributed under the Creative Commons Attribution License, which permits unrestricted use, distribution, and reproduction in any medium, provided the original work is properly cited.

Red clay slopes have different failure modes in different geological and climatic contexts. Underlying weak layers are frequently witnessed in integral failures because of the reverse consolidation characteristics. On the contrary, heavy rainfall often causes superficial sliding for a considerable infiltration through developed microfractures. Based on the Geographic Information System, regional stability of red clay slopes was evaluated with two failure modes, such as "integral sliding" and "planar sliding." First, terrain and borehole data of the study area were used to construct the digital elevation model. Second, slope units were partitioned as research objects. For integral sliding, the slip surface was supposed to lie above the strata interface, and it was regarded as a lower part of an ellipsoid. After calculating safety factors of potential slip surfaces that were randomly generated by the Monte Carlo method, the minimum safety factor of the slope unit and the critical slip surface could be determined. For shallow landslides triggered by rainfall infiltration, the onedimensional infiltration model and infinite slope model were used. Moreover, the difference between the sliding direction of each column and the main aspect of entire slope unit was considered in safety factor calculation. Finally, regional slope stability characterized by the safety factor would be available; thus, it would be beneficial to sliding prevention and disaster treatment in this region.

\section{Introduction}

Red clay, a kind of high plastic clay that always appears in tropical and subtropical areas with warm-wet climate, is usually formed by carbonate rock after weathering and laterization. The distribution regions mainly locate in Asian and African countries between $30^{\circ} \mathrm{N}$ and $30^{\circ} \mathrm{S}$. In recent years, red clay has also been found in north-east Asia, such as Dalian and Fukuoka. Like other clays, red clay presents a high liquid-plastic limit and a high water content. Moreover, as depth increases, shear strength and preconsolidation pressure reduce. Though red clay appears to be soft and porous, it might be accompanied with a quite high overconsolidation ratio and good compressive strength. The superficial layer often appears to be a hard shell lying on weak substratum [1]. Therefore, these properties are quite different from common clays that have experienced the normal consolidation process. Because of the particularities, how to define the failure modes under different situations and how to evaluate the stability of red clay slopes with different failure modes are of great significance.

Engineering characterization of slope stability, such as safety factor and stability factor, is based on specific failure modes. For instance, safety factors calculated by the Swedish method and simplified Bishop method are only applicable in the circular sliding mode. On the contrary, stability factor of soil slope in limit analysis suits for logarithmic spiral sliding. Given the sliding mode in advance, potential slip surfaces could be searched with corresponding safety or stability factors; finally, the most dangerous slip surface could be determined. Many researches were performed to investigate the relationship between slope reliability and destabilization modes for soil or rock materials [2-4]. As powerful forecasting tools of rainfall-induced shallow landslides, some 
physically based models, such as SHALSTAB ${ }^{\circledR}$ [5], SINMAP ${ }^{\circledR}$ [6], SLIP ${ }^{\circledR}$ [7], and TRIGRS ${ }^{\circledR}$ [8], were conducted and used in stability analyses on a regional scale [9-12]. Both models assume the hypothesis of infinite slope with the presence of superficial and translational soil slips, as well as the one-dimensional infiltration model. In general, because of the rich application and simple algorithm, the plane strain model is usually adopted to calculate the slope safety factor. However, the planar model has some inherent defects: (1) selection of the trial section is subjective and inaccurate, (2) boundary constraints of slices are significantly simplified, and (3) real-sliding direction often intersects with the calculation plane.

Due to in-built powerful functions and tools, Geographic Information System (GIS) has been applied more and more widely in landslide hazard assessment [13-21]. Some researchers used GIS, incorporating with the mechanical analysis model, to perform regional slope stability analysis [22-24]. In these researches, on the basis of spatial analysis functions of GIS, all slope stability-related data of the whole study area can be presented as raster layers with requisite precision, such as elevation, aspect, inclination, water table, and interface. Both geological information and mechanical parameters could be denoted in cluster of stratum columns. After inputting these data into a deterministic model of slope stability analysis, a value of the safety factor could be obtained.

As a kind of special soil, field investigation showed that there are two typical failure modes of red clay slopes: integral sliding along stratum interface and shallow planar sliding caused by rainfall infiltration. Theoretically, different evaluation models should be established for different failure modes because the general calculation model cannot reflect distinct working conditions. Consequently, it is necessary to perform a research on landslide mechanism, failure mode, and calculation method for red clay slopes. Meanwhile, the algorithm should be improved to overcome aforementioned defects in three-dimensional analysis. In this article, physical and mechanical properties of typical red clay were introduced; besides, "reverse profile" and its formation mechanism were interpreted. Subsequently, two typical failure modes of red clay slopes were proposed. Furthermore, regional slope stability analysis methods for different failure modes were established by incorporating with Geographic Information System (GIS). Conclusively, applicability of the proposed method was verified with a practical engineering case.

\section{Materials and Methods}

\subsection{Properties of Red Clay}

2.1.1. Composition and Microstructure. The main mineral compositions of red clay are $\mathrm{Al}_{2} \mathrm{O}_{3}(12 \% \sim 48 \%)$ and $\mathrm{Fe}_{2} \mathrm{O}_{3}$ $(3.3 \% \sim 12 \%)$. However, the total proportion of $\mathrm{Al}_{2} \mathrm{O}_{3}$ and $\mathrm{Fe}_{2} \mathrm{O}_{3}$ in carbonate bedrock is less than $1 \%$. Therefore, $\mathrm{Al}_{2} \mathrm{O}_{3}$ and $\mathrm{Fe}_{2} \mathrm{O}_{3}$ are significantly enriched during weathering formation of red clay on carbonate bedrock. $\mathrm{SiO}_{2}$ is the secondary composition in carbonate rock (about 3\%); however, it also enriches up to $23 \% \sim 68 \%$ in red clay.

Basic microstructure unit of red clay is the aggregate of clay mineral slices. The aggregate is always porous and saturated, owning good mechanical properties. Electrostatic attraction and cementation of free oxides keep the aggregate stable. Moreover, small aggregate units form larger ones by cementing each other. It is the basic distinction between microstructure of red clay and of other clays, which could explain the contradiction of physical properties and mechanical strength of red clay.

Aggregates are irregularly shaped with a scale of $1 \mu \mathrm{m} \sim 5 \mu \mathrm{m}$. Under general engineering loads, compression of red clay is mainly caused by displacement of aggregate units rather than collapse of aggregates. Similarly, shearing of red clay depends on dislocation of aggregates rather than destruction of aggregate itself.

Free oxides, such as $\mathrm{Fe}_{2} \mathrm{O}_{3}, \mathrm{Al}_{2} \mathrm{O}_{3}$, and $\mathrm{SiO}_{2}$, especially $\mathrm{Fe}_{2} \mathrm{O}_{3}$, are cementing substances that caused the aforementioned particularities of red clay. They combine with clay materials (kaolinite, illite, etc.) through electrostatic attraction. Free oxides affect the porosity either. Without cementing substances, the aggregates separate and pores collapse. Tests showed that porosity of red clay samples reduces dramatically after removing free $\mathrm{Fe}_{2} \mathrm{O}_{3}$.

Furthermore, the SIEMENS D500 X-ray diffractometer was used to perform quantitative analysis of chemical composition in red clay samples of Quangzhou (Hubei Province), and the results are shown in Tables 1 and 2. It could be concluded that the dominant clay minerals are kaolinite, illite, and chlorite, while main nonclay minerals include quartz and feldspar. In addition, the major chemical components are $\mathrm{SiO}_{2}, \mathrm{Al}_{2} \mathrm{O}_{3}$, and $\mathrm{Fe}_{2} \mathrm{O}_{3}$.

\subsubsection{Reverse Profile of Red Clay Stratum and Formation} Mechanism. As depth increases, the mechanical strength of red clay reduces. Upper layer seems like a rigid shell lying beneath weak layers. These are just contrary to normally consolidated stratum, the strength and density of which keep increasing downwardly due to drainage consolidation. Thus, it is called "reverse profile characteristics." Some results of the typical red clay are given in Table 3.

(1) Generally speaking, statuses of red clay layers gradually change from hard to flow plastic downwardly, though some layers might be absent.

(2) As depth increases, contents of $\mathrm{SiO}_{2}, \mathrm{Al}_{2} \mathrm{O}_{3}$, and $\mathrm{Fe}_{2} \mathrm{O}_{3}$ reduce, whereas contents of $\mathrm{CaO}$ and $\mathrm{MgO}$ increase significantly. As cementing materials, they affect the consolidation degree of red clay.

(3) As depth increases, water content, void ratio, liquid limit, liquidity index, as well as plastic index increase. On the other hand, density, plastic limit, and shear strength gradually reduce.

(4) As depth increases, the compression modulus of red clay decreases. On the contrary, preconsolidation pressure, as well as the overconsolidation ratio (OCR), decreases. 
TABLE 1: Element composition.

\begin{tabular}{lccccccccc}
\hline Element & $\mathrm{O}$ & $\mathrm{Si}$ & $\mathrm{Al}$ & $\mathrm{Fe}$ & $\mathrm{C}$ & $\mathrm{K}$ & $\mathrm{Mg}$ & $\mathrm{Na}$ & $\mathrm{Ca}$ \\
\hline Content (\%) & 48.2 & 17.8 & 14.1 & 9.3 & 5.5 & 1.7 & 1.2 & 0.7 & 0.3 \\
\hline
\end{tabular}

TABLe 2: Mineral composition.

\begin{tabular}{lcccccc}
\hline Mineral & Kaolinite & Illite & Chlorite & Montmorillonite & Quartz & Feldspar \\
\hline Content (\%) & 25.3 & 17.5 & 14.4 & 1.3 & 30.2 & 9.6 \\
\hline
\end{tabular}

Table 3: Profile distribution of some indexes of red clay.

\begin{tabular}{|c|c|c|c|c|c|c|c|c|}
\hline Depth (m) & $\begin{array}{c}\text { Water } \\
\text { content }(\%)\end{array}$ & $\begin{array}{l}\text { Density } \\
\left(\mathrm{g} / \mathrm{cm}^{3}\right)\end{array}$ & Void ratio & $\begin{array}{l}\text { Liquid-plastic } \\
\text { limit (\%) }\end{array}$ & $\begin{array}{c}\text { Preconsolidation } \\
\text { pressure }(\mathrm{kPa})\end{array}$ & $\begin{array}{c}\text { Overlying } \\
\text { pressure }(\mathrm{kPa})\end{array}$ & OCR & $\begin{array}{l}\text { Compression } \\
\text { modulus }(\mathrm{MPa})\end{array}$ \\
\hline $3-4$ & $27.4 / 32.0$ & 2.06 & $0.75 / 0.83$ & $57.5,24.3 / 40.5,26.3$ & $320 / 370$ & $74 / 78$ & $\begin{array}{l}4.32 / \\
4.74\end{array}$ & 10.23 \\
\hline $4-5$ & $28.2 / 32.4$ & 1.97 & $0.78 / 0.84$ & $58.8,28.6 / 41.4,25.2$ & $306 / 353$ & $93 / 95$ & $\begin{array}{l}3.29 / \\
3.72\end{array}$ & 9.95 \\
\hline $6-7$ & $29.6 / 32.9$ & 1.92 & $0.81 / 0.86$ & $61.8,30.0 / 41.2,25.3$ & $290 / 340$ & $132 / 132$ & $\begin{array}{l}2.20 / \\
2.58\end{array}$ & 9.53 \\
\hline $9-10$ & $32.4 / 33.5$ & 1.86 & $0.89 / 0.88$ & $66.5,25.8 / 40.3,24.3$ & $280 / 324$ & $190 / 192$ & $\begin{array}{l}1.54 / \\
1.69\end{array}$ & 8.68 \\
\hline $10-11$ & $35.2 / 33.9$ & 1.85 & $0.95 / 0.91$ & $65.9,34.7 / 40.2,20.7$ & $274 / 312$ & $212 / 210$ & $\begin{array}{l}1.29 / \\
1.49\end{array}$ & 7.22 \\
\hline $12-13$ & $37.3 / 38.7$ & 1.81 & $0.99 / 0.97$ & $66.9,28.0 / 39.2,21.4$ & $262 / 308$ & $252 / 230$ & $\begin{array}{l}1.04 / \\
1.34\end{array}$ & 5.96 \\
\hline
\end{tabular}

In general, consolidation of soil depends on the maximum depth that is ever experienced. However, consolidation of red clay is not primarily controlled by overlying pressure. Red clay experiences two geochemistry periods during the formation process, namely, karstification and laterization. Karstification is local reformation of dissolved residues, and laterization is construction of microstructure downwardly. Insoluble $\mathrm{SiO}_{2}, \mathrm{Al}_{2} \mathrm{O}_{3}$, and $\mathrm{Fe}_{2} \mathrm{O}_{3}$ are leached, accumulated, and gelled constantly during laterization accompanied with dry-wet cycling. Loose soil particles are cemented and dyed by $\mathrm{Fe}_{2} \mathrm{O}_{3}$, and finally aggregates with high water resistance and mechanical strength come into being. Laterization is mainly influenced by climate, depth, and duration. The deeper the red clay locates, the less influence it suffers. Because the content of free $\mathrm{Fe}_{2} \mathrm{O}_{3}$ reduces downwardly on the profile, the cementation weakens, and equivalent preconsolidation pressure becomes smaller. Overall, the consolidation process of red clay characterizes enhancement of structural strength and improvement of mechanical properties (including physical and chemical consolidation), rather than simple recordation of historical overlying pressure $[25,26]$.

\subsection{Failure Modes of Red Clay Slope}

2.2.1. Integral Sliding Based on Weak Interface. Though engineering slopes of red clay always appear to be solid and well maintained, there might be some weak interfaces inside. Weak interfaces of red clay could be roughly classified into two types, as shown in Figure 1: (1) due to reverse consolidation characteristics, the lower layer has a lower shear strength. Consequently, slope failure often occurs along the surface of soft substratum; (2) located on carbonate bedrock, the interface between bedrock and upper red clay layer always constitutes a part of the slip surface [27]. Moreover, red clay has moderate contractility, and cracks also facilitate landslides. In addition, because of the depth variation of stratum, a certain layer might be absent at some sites.

2.2.2. Planar Sliding Based on Rainfall Infiltration. Experience has shown that many red clay landslides occur during or shortly after intensive rainfall. These failures are characterized by relatively shallow slip surfaces (typically $1 \mathrm{~m}$ to $3 \mathrm{~m}$ deep) that develop parallel to the original slope surface (as shown in Figure 2). The groundwater table is usually located at a considerable depth below the ground surface, and there is no evidence that shows that heavy rainfall causes a rise of the water table that is sufficient to trigger these shallow failures. Instead, these landslides might be attributed to the deepening of a wetting front intruding into the slope due to rainfall infiltration.

\subsection{Regional Slope Stability Analysis Based on GIS}

2.3.1. Identification of Slope Unit. Traditional quantitative methods of slope stability analysis concentrate on single slopes. A fundamental problem in regional slope stability analysis is the identification of research objects. Because of the complexity of outline of slope body, determination of slip surface, manipulation of massive spatial data, and visualization of analysis results, it is quite difficult to extract or clarify research objects within large areas. 


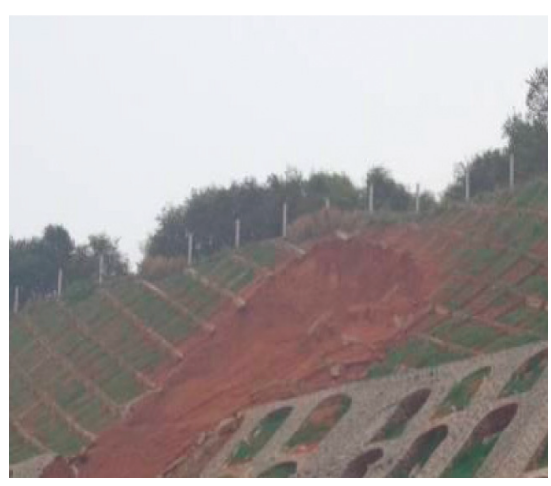

(a)

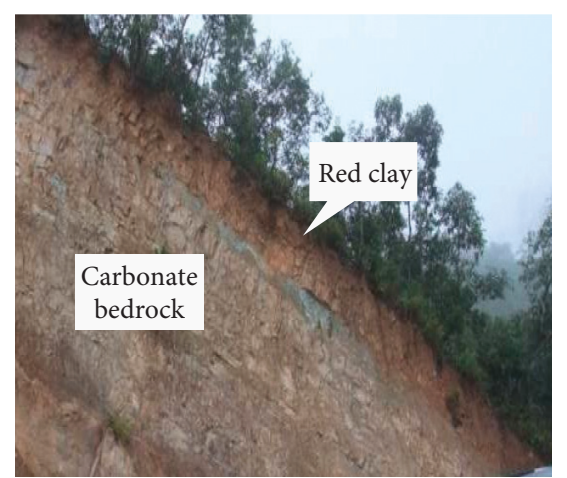

- Rigid layer

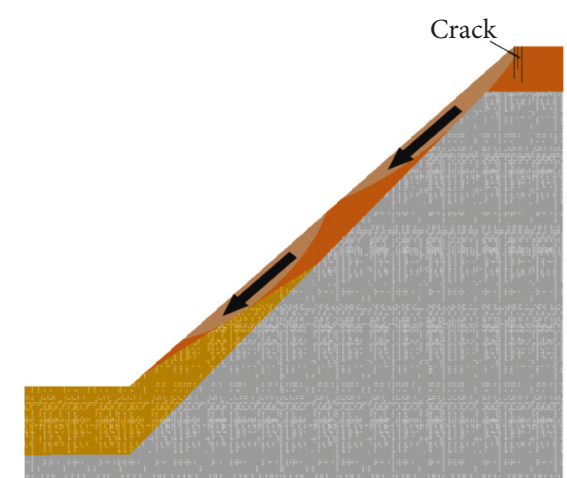

- Soft layer

- Bedrock

(c)

FIGURE 1: Integral sliding along the stratum interface.

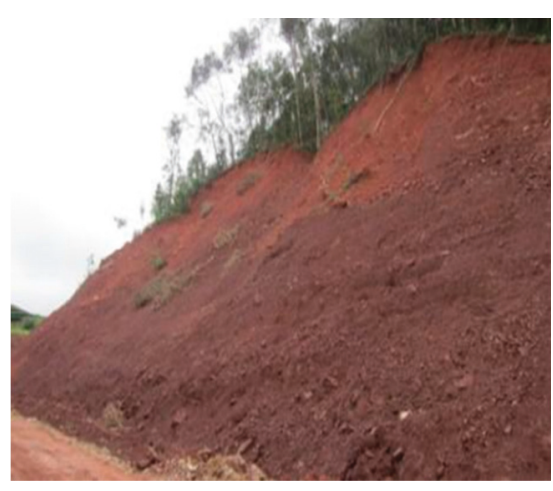

(a)

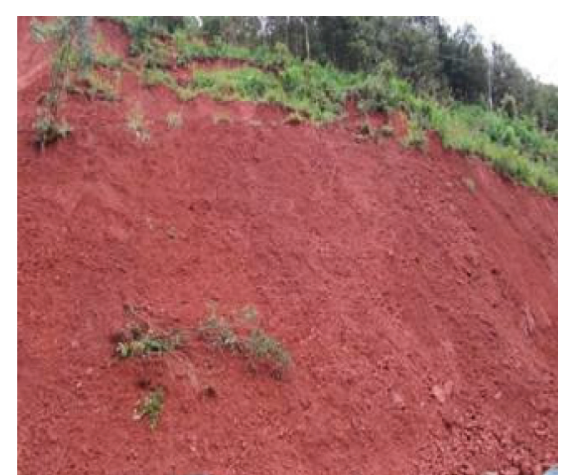

(b)

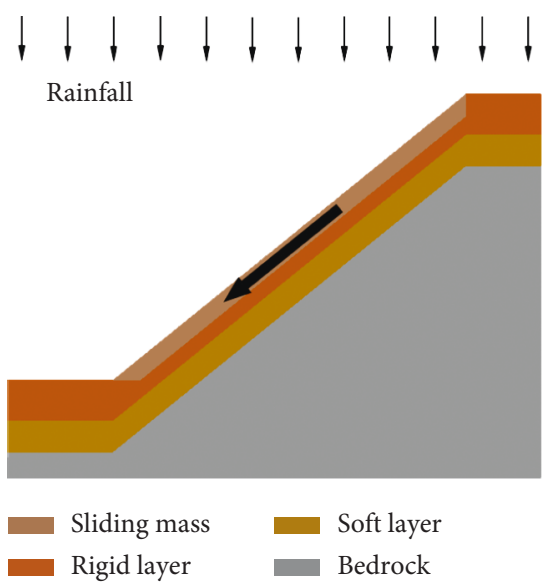

(c)

Figure 2: Planar sliding under rainfall.

For regional slope stability analysis with suitable extraction of the study objects in a mountainous area, not only geology and hydrology but also terrain conditions, such as aspect and inclination, should be taken into consideration. Slope unit, a portion of the land surface which contains a set of terrain conditions that differ dramatically from adjacent units beside definable borderline, is proposed to partition the region for assessment. Grid columns in a slope unit possess similar topographic characteristics; thus, a clear physical relationship between landslide occurrences and the basic morphological elements could be established.

Slope unit can be regarded as either side of a subbasin of any order into which a watershed can be partitioned; therefore, it can be identified topologically by a ridge line and a valley line. In order to perform regional slope stability analysis efficiently, these terrain lines should be quickly identified out of massive digital elevation data. By using the hydraulic model tool of GIS, the watershed polygons of the study area can be obtained easily from the digital elevation model (DEM) file by setting the specific threshold accumulation value which depends on field investigation and solving precision. Topologically, the outline of the watershed polygon can be considered as the ridge line; on the contrary, the reversed DEM is used to obtain the valley line. Consequently, the valley line divides the former watershed polygon into two slope units (Figure 3 ).

2.3.2. Regional Integral Sliding Model Based on GIS. There are countless possibilities for slip surface location in landslides, and the most dangerous one would be the true slip surface. Theoretically, the most dangerous slip surface could be definitely obtained with the minimum safety factor after enough times of trial calculations, which might be unacceptable for manual computation. Fortunately, with the help of multiple functions provided by GIS, it is feasible to determine the most dangerous slip surface by numerous trial calculations. The slip surface is regarded to be a lower part of an ellipsoid, which would be replaced if the ellipsoid locates beneath the surface of stratums or cracks. As shown in 


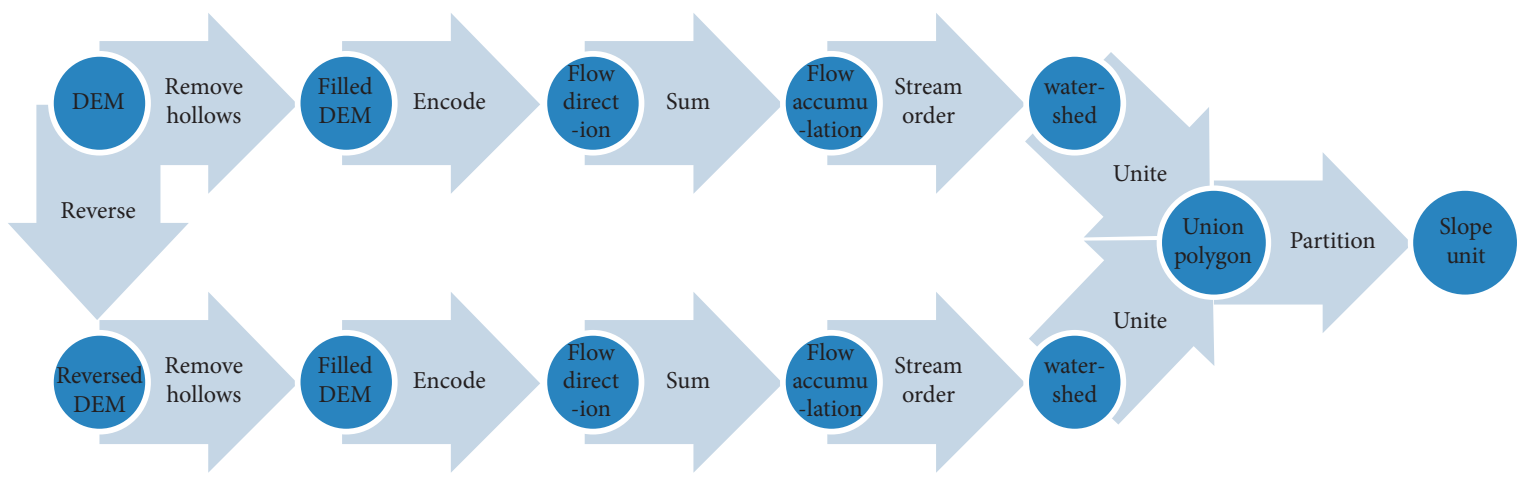

FIgURE 3: Obtainment of slope unit.

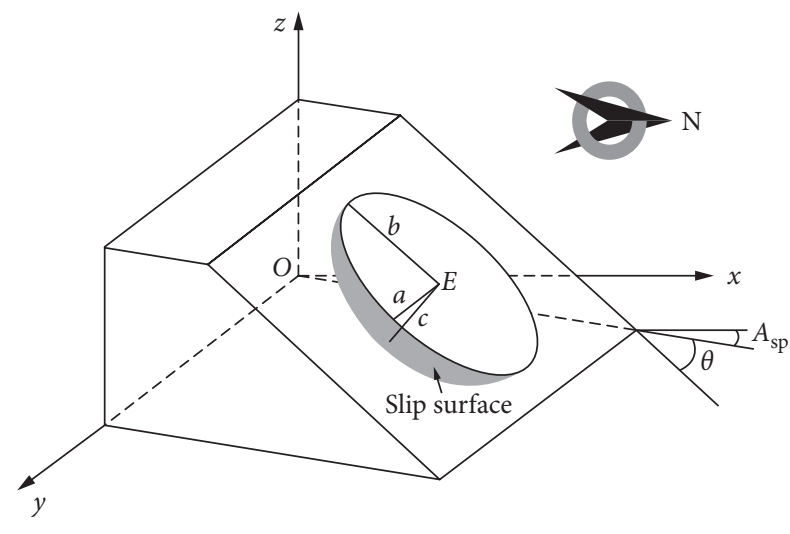

Figure 4: Attitude control of ellipsoid.

Figure 4, the attitude of the ellipsoid could be controlled by 8 parameters: coordinates $(x, y, z)$ of ellipsoid center (point $E$ ), spans of ellipsoid in three dimensions $(a, b, c)$, inclination $(\theta)$, and aspect $\left(A_{\mathrm{sp}}\right)$, which are randomly generated by the Monte Carlo method. For simplification, the aspect of ellipsoid equals to the main aspect of the slope unit and the $z$ coordinate equals to the elevation of the slope surface by default. As shown in Figure 5, points in the "point data" of each slope unit, which is composed of a large number of elevation points locating on the slope surface and appearing to be square nets horizontally, were selected as the center points of ellipsoid successively (Figure 5(b)). For each trial center point, aforementioned parameters generated by the Monte Carlo method could be used to obtain the potential slip surface (Figure 5(c)). For each slope unit, after the safety factors of all potential slip surfaces were obtained, the critical slip surface with the minimum safety factor could be recognized (Figure 5(d)).

Three-dimensional Hovland model was based on an extension of the Ordinary Method of Slices and could give an explicit solution of the slope safety factor [28]. However, it was not accurate enough in some cases for neglecting normal stress on vertical interfaces [29]. An improved model was put forward after modifying the computation of vertical force on the element sliding surface in the Hovland model. It presents an explicit solution, which benefits a lot to the implementing of the GIS extension module. Moreover, the result is closer to the solutions obtained by Bishop 3D and
Janbu 3D models [30]. The improved Hovland model could be stated as follows:

$$
F_{\mathrm{S}}=\frac{\sum_{J} \sum_{I}\left\{c A+\left[\gamma^{\prime} d^{2}\left(Z_{i j}-z_{i j}\right) \cos \theta_{A v r}-u_{i j} A\right] \tan \varphi\right\}}{\sum_{J} \sum_{I} \gamma^{\prime} d^{2}\left(Z_{i j}-z_{i j}\right) \sin \theta_{A v r}},
$$

in which $F_{\mathrm{s}}$ is the safety factor, $Z_{i j}$ and $z_{i j}$ are the elevations of the ground and slip surface $(\mathrm{m}), u_{i j}$ is the underground water pressure acting on slip surface $(\mathrm{kPa}), \theta_{A v r}$ is the inclination of slip surface along main aspect of slope unit $\left({ }^{\circ}\right), d$ is the grid size $(\mathrm{m}), A$ is the area of slip surface $\left(\mathrm{m}^{2}\right), c$ is the cohesion of soil $(\mathrm{kPa}), \varphi$ is the friction angle of soil $\left({ }^{\circ}\right)$, and $\gamma^{\prime}$ is the effective weight $\left(\mathrm{kN} / \mathrm{m}^{3}\right)$. In order to implement the algorithm and obtain the integral safety factors of all slope units, an extension module was developed and implanted in ArcGIS on the basis of Visual Basic 6.0 of Microsoft ${ }^{\circledR}$ and ArcObject of ESRI ${ }^{\circledR}$. The flowchart of solution to regional integral landslides is illustrated, as shown in Figure 6.

2.3.3. Regional Planar Sliding Model Based on GIS. Methods in studying landslides caused by rainfall could be classified into two types: empirical probabilistic method and deterministic method. The empirical probabilistic method usually presents a statistical correlation of historical landslide records; instead, the deterministic approach establishes a simplified infiltration model to reflect the natural process. Though empirical methods do not have to explain the mechanism of rainfall-induced landslides and benefited a lot to engineers, they provide no general and theoretical framework for understanding when and where the slope failure would be activated by rainfall. In addition, an empirical model established for a specific region is often unreliable while applying in a different area due to different geotechnical and climatic conditions. Conclusively, further research on the triggering mechanism of rainfall and corresponding deterministic model will certainly be helpful to the prediction and prevention of rainfall-induced slope failures.

During past decades, various solutions to the unsaturated seepage problem have been developed; however, one-dimensional infiltration model (such as the Green- 


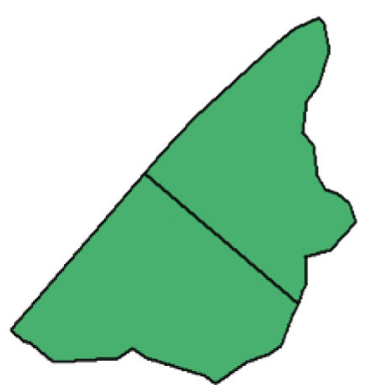

(a)

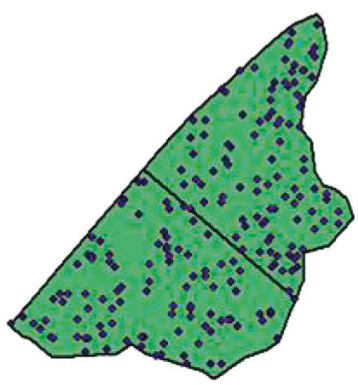

(b)

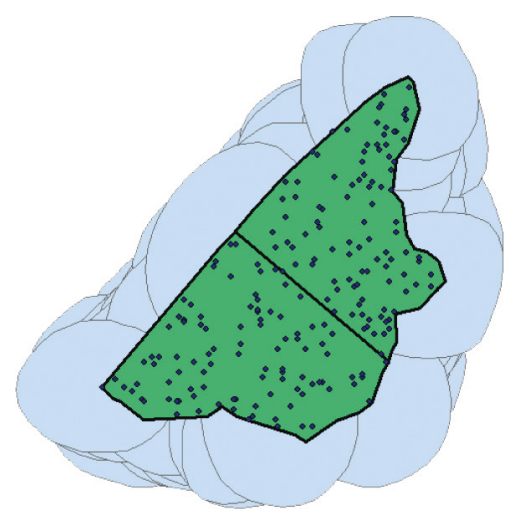

(c)

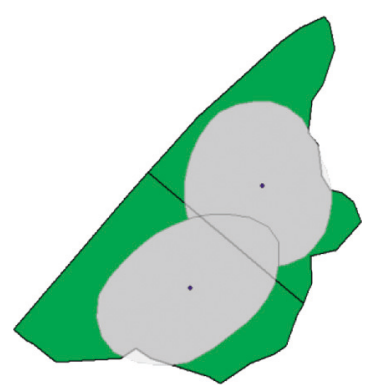

(d)

FIGURE 5: Obtainment of critical slip surface of slope units: (a) slope unit division; (b) center points of ellipsoids; (c) trial slip surfaces; (d) the most dangerous slip surface.

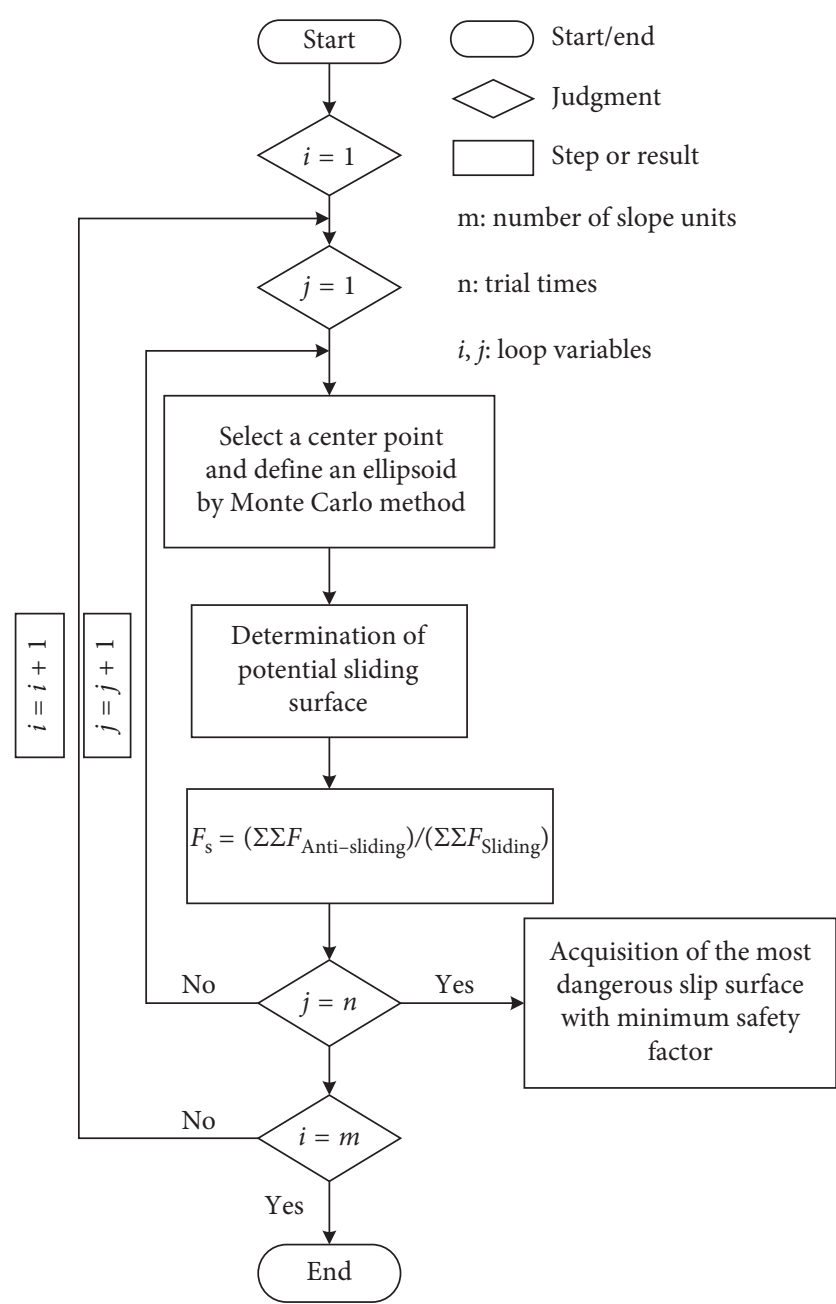

FIGURE 6: Flowchart of regional integral sliding of slope based on GIS.

Ampt model) remains in common use due to its widely accepted concepts of soil physics and simple algorithm. Moreover, deterministic modeling of regional slope stability mainly adopted the infinite slope model assuming that landslides are infinitely long in length; thus, it is typically suitable for landslides with shallow planar slip surfaces. As shown in Figure 7, $\alpha$ is the bottom inclination of soil slice $\left({ }^{\circ}\right)$, which equals to inclination of slope surface, $H$ is the infiltration depth $(\mathrm{m}), \gamma_{\text {sat }}$ is the unit weight of saturated soil $\left(\mathrm{kN} / \mathrm{m}^{3}\right), c^{\prime}$ and $\varphi^{\prime}$ are the effective cohesion $(\mathrm{kPa})$ and effective friction angle $\left({ }^{\circ}\right)$ of infiltrated layer, $\varphi^{\mathrm{b}}$ is the friction angle attributed by matric suction $\left({ }^{\circ}\right), A_{\mathrm{c}}$ is the cross-sectional area of soil slice $\left(\mathrm{m}^{2}\right), W$ is the weight of slice $(\mathrm{kN})$, and $\sigma_{n}$ and $\tau$ are the normal and shear stresses acting on the bottom of slice $(\mathrm{kPa})$.

To build practical relationship between landslide phenomenon and natural terrain, the slope unit is also introduced as the elementary study object in planar sliding. Sliding mass could be regarded as a cluster of sliding columns. Since "aspect" characterizes the direction with steepest inclination of a column, the main aspect of all columns in a slope unit is regarded as the actual sliding direction. Aspects of all columns in the slope unit vary moderately, and they intersect the main aspect with an angle. Considering the difference of sliding direction between each column and the entire sliding mass, the safety factor could be calculated using the following equation:

$$
F_{\mathrm{S}}=\frac{c^{\prime}+\gamma_{\mathrm{w}} h_{\mathrm{f}} \tan \varphi^{\mathrm{b}}}{\left(\gamma_{\mathrm{sat}} H+\gamma_{\mathrm{w}} h_{\mathrm{f}}\right) \sin \alpha \cos \alpha \cos (\Delta \delta)}+\frac{\tan \varphi^{\prime}}{\tan \alpha},
$$

in which the Green-Ampt model is incorporated, $\Delta \delta$ represents the intersection angle of sliding direction $\left(^{\circ}\right), \gamma_{\mathrm{w}}$ is the unit weight of water $\left(\mathrm{kN} / \mathrm{m}^{3}\right)$, and $h_{\mathrm{f}}$ is the matric suction at the wetting front $(\mathrm{m})$. A flow chart of solution to regional planar landslides could be illustrated, as shown in Figure 8, in which all the data management, spatial analysis, and calculations could be accomplished in the ArcGIS framework.

\section{Analyses and Results}

As shown in Figure 9, the study area, selected from Taizaifu district in Fukuoka, is covered with a residual layer of red clay. The highway meanders around the west edge of the hill. 


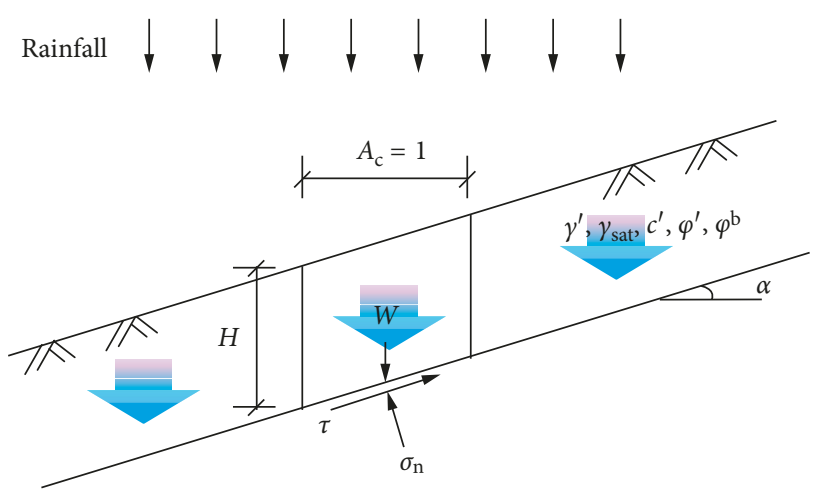

FIgURE 7: Infinite seepage model of unsaturated slope.

As data preparation, the aerial and field investigations were carried out, and a rich supply of elevation data was obtained. After necessary data processing by the spatial analysis tool of GIS, the raster file of the digital elevation model (DEM) was derived with a resolution of $5 \mathrm{~m}$. Figure 9 also shows three sections of the mountainous area, with variant spans from $550 \mathrm{~m}$ to $780 \mathrm{~m}$. The average inclination of the hill is about $1: 2.5$. According to site investigation, the slope area can be roughly divided into three strata: upper rigid red clay (depth range: $0 \mathrm{~m} \sim 2.5 \mathrm{~m}$ ), lower weak red clay (depth range: $2.5 \mathrm{~m} \sim 8 \mathrm{~m}$ ), and bedrock. The physical and mechanical parameters of strata used in analysis are given in Table 4 .

Aiming at evaluating potential slope failures that might be harmful to the highway traffic, the mountainous area was divided into two parts by specific ridge lines: one part in which the sliding mass might cause danger to the traffic safety; the other part, in which the sliding mass would not move toward the highway when slope failure occurs, was not taken into account in following study. By using spatial analyst tools of GIS, research range was identified in advance. Subsequently, slope units were partitioned as enclosed areas by following the aforementioned procedure. As shown in Figure 10, red lines finally sketched the contours of all slope units sharply in the study area.

Taking advantage of the data processing and mapping functions of GIS, regional slope stability assessment characterized by the safety factor was illustrated (Figure 11). One hundred trial calculations for each slope unit were designated in integral sliding, and the infiltration depth is specified to be $1.8 \mathrm{~m}$ in planar sliding. Critical slope units could be easily recognized by $F_{\mathrm{s}}<1.00$ and following study on certain slope unit or potential influencing range could be carried out.

There are differences between critical landslide zones $\left(F_{\mathrm{s}}<1.00\right)$, as shown in Figures 11(a) and 11(b). The primary reasons are as follows: (1) maps were illustrated on the basis of different failure modes, respectively; (2) the mapping element of integral sliding was slope unit rather than pixel in planar sliding; (3) potential sliding mass is generated randomly by the Monte Carlo method; for instance, $100 \mathrm{el}-$ lipsoids were created and trialed for each slope unit by

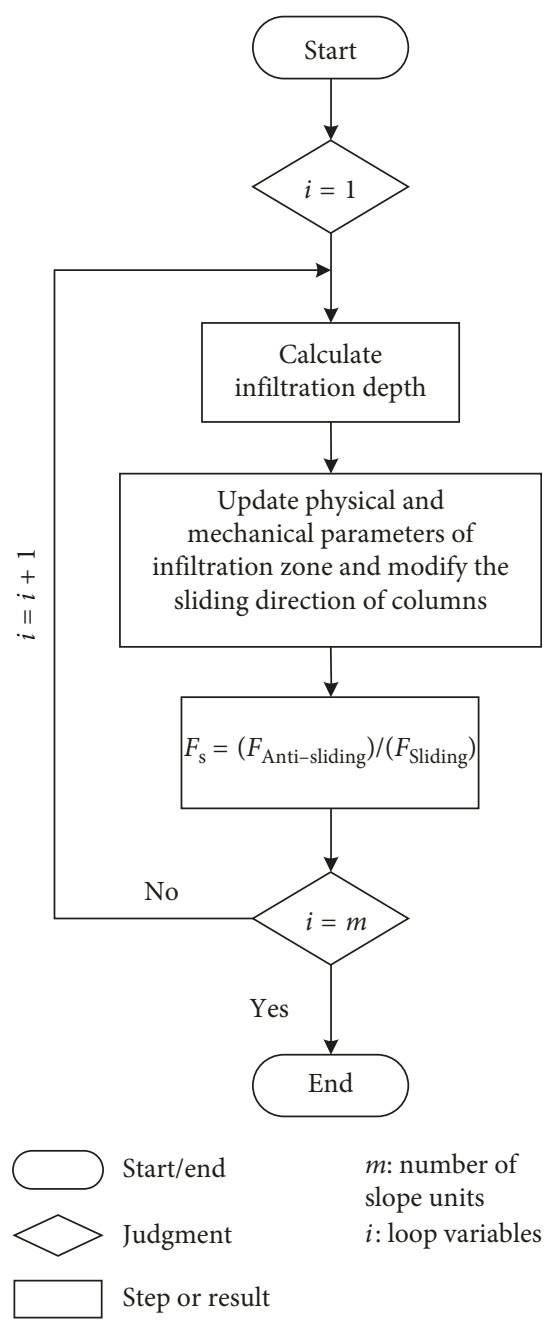

FIGURE 8: Flowchart of regional planar sliding of slope based on GIS.

adjusting the size and attitude parameters. Theoretically, the actual slip surface would be figured out precisely after enough times of trials.

Eventually, the research successfully predicted the location of a rainfall-induced landslide occurrence marked in Figure 11(c), which resulted in one fatality and several injuries. According to the accident investigation, the slide bed located much higher than the groundwater level. The slope failure was primarily caused by rain wash and seepage force acting on the upper layer. Once the slope foot was destabilized, the soil mass behind it lost support and followed to move, and finally the landslide extended backwards.

Moreover, combined with the infiltration model, regional slope stability under lasting rainfall could be evaluated by mapping the spatial-temporal deterioration of safety factor. However, landslides are natural disasters with occasional and random characteristics, such as soil inhomogeneity and vegetation coverage. Though all of the theoretically potential landslides represented by red areas or spots in these maps $\left(F_{s}<1.00\right)$ may not occur simultaneously 

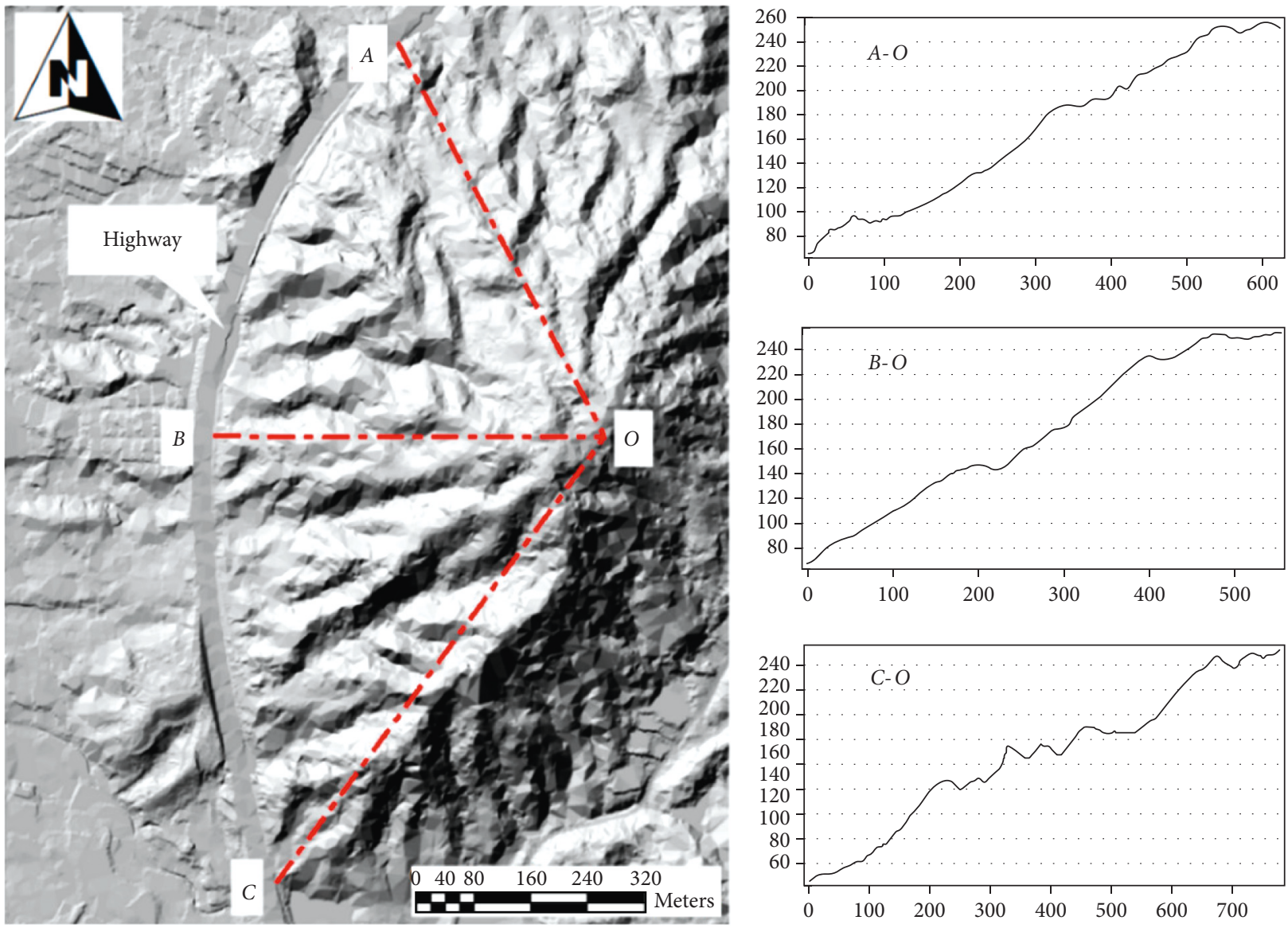

Figure 9: Hillshade of the study area (unit: m).

Table 4: Physical and mechanical indexes of red clay and bedrock.

\begin{tabular}{lcccccccc}
\hline Item & $c(\mathrm{kPa})$ & $c^{\prime}(\mathrm{kPa})$ & $\varphi\left(^{\circ}\right)$ & $\varphi^{\prime}\left(^{\circ}\right)$ & $\varphi^{\mathrm{b}}\left(^{\circ}\right)$ & $h_{\mathrm{f}}(\mathrm{m})$ & $\gamma\left(\mathrm{kN} / \mathrm{m}^{-3}\right)$ & $\gamma_{\mathrm{sat}}\left(\mathrm{kN} / \mathrm{m}^{-3}\right)$ \\
\hline Upper red clay & 36.7 & 15.8 & 15.4 & 11.7 & 8.4 & 0.63 & 19.1 & 20.8 \\
Lower red clay & 24.1 & 11.6 & 14.8 & 9.6 & 8.2 & 0.42 & 18.5 & 20.3 \\
Bedrock & 5000 & - & 40 & - & - & - & - \\
\hline
\end{tabular}

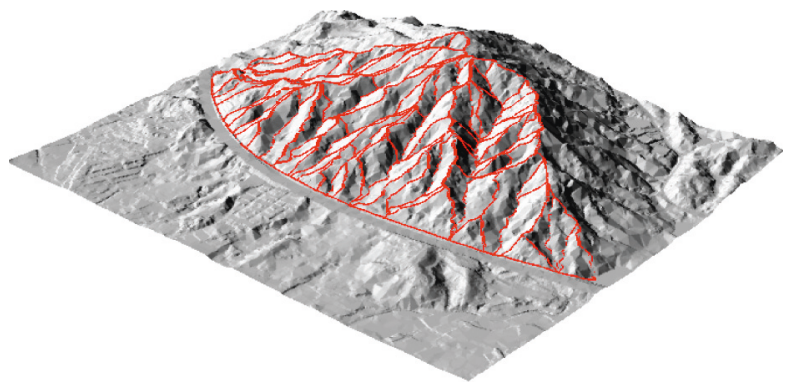

FIgURE 10: Slope unit division of the study area.

in few geological hazard periods, it will still benefit a lot to narrowing critical ranges and centralizing preventive measures by overlaying two zonation maps. Combining different thematic maps such as land use or residential distribution, more information or details might be acquired, and then comprehensive assessment based on these data would be beneficial for sliding prevention and disaster treatment in the study area. 


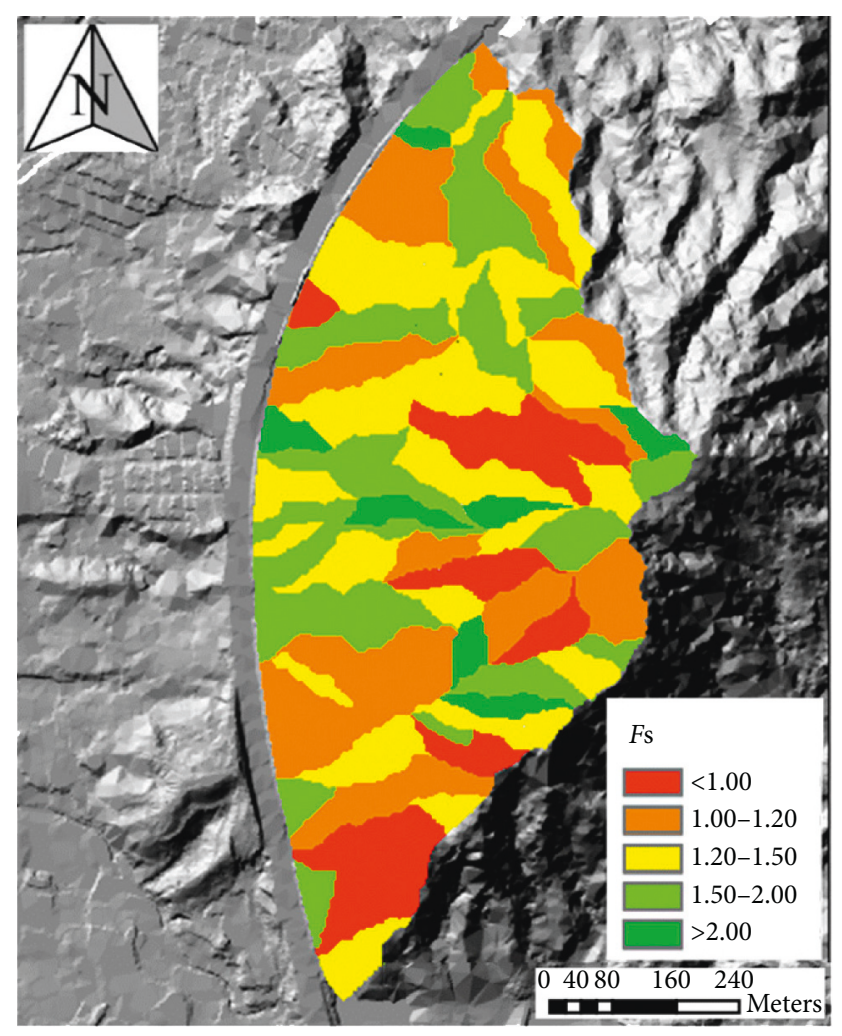

(a)

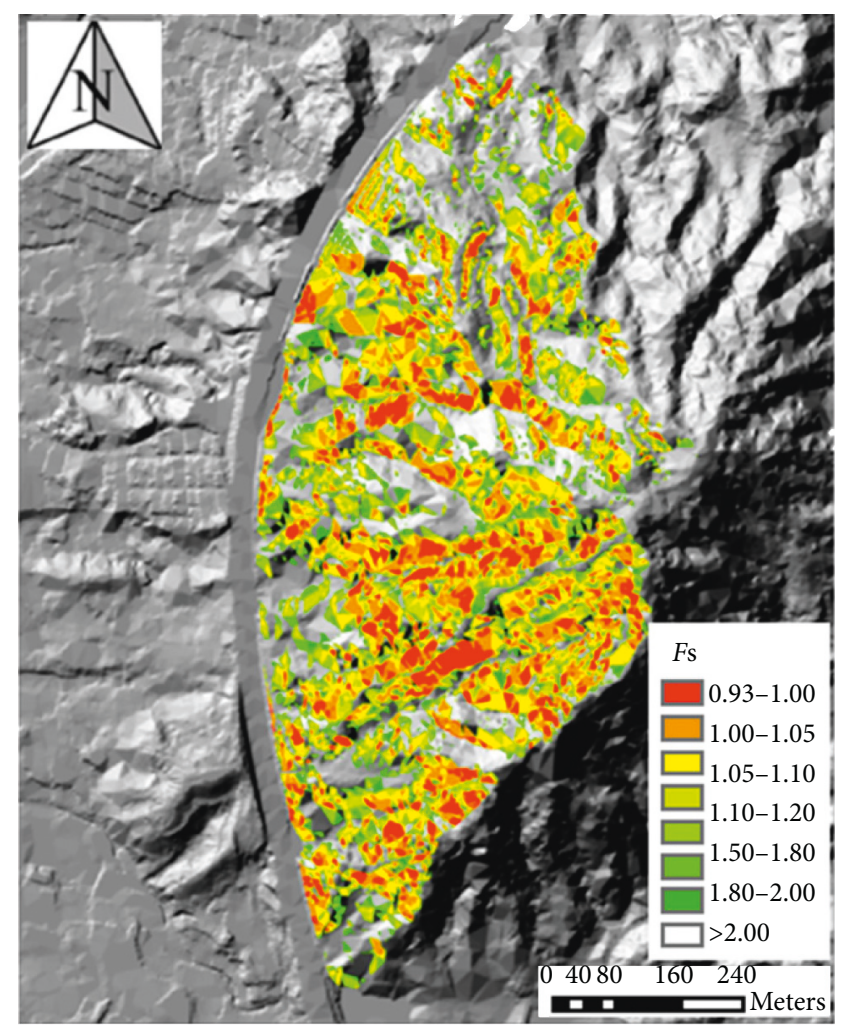

(b)

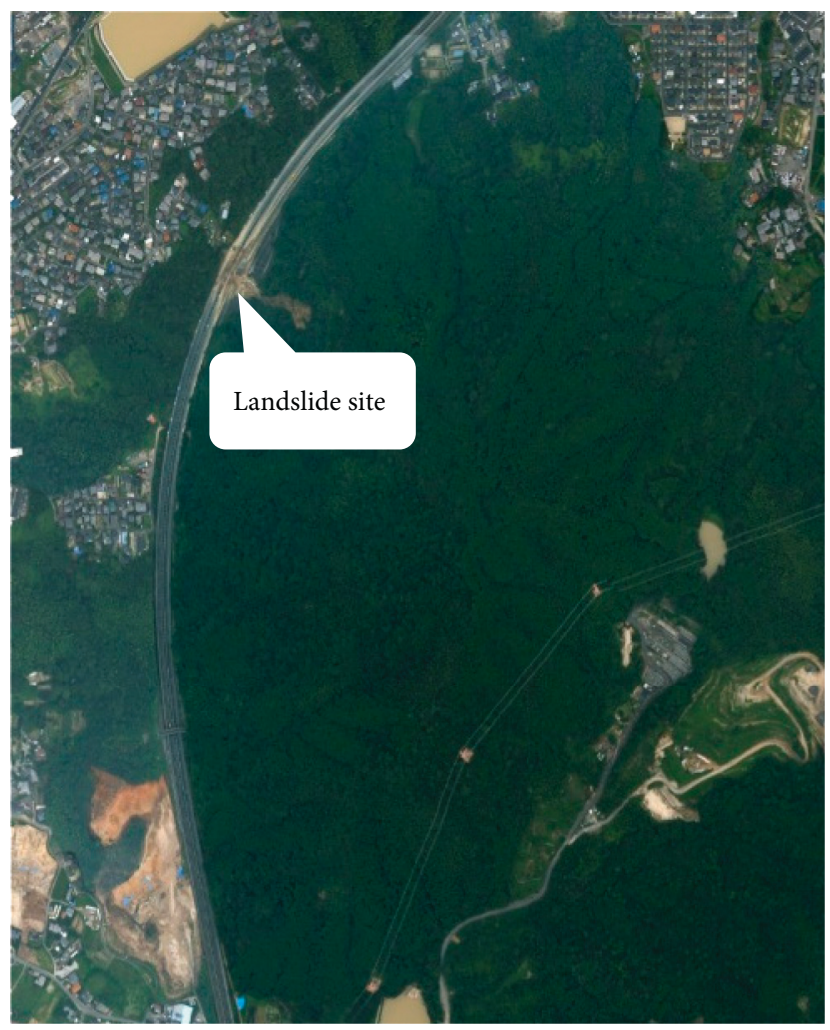

(c)

FIgURE 11: Maps of regional slope stability: (a) integral sliding; (b) planar sliding; (c) landslide occurrence. 


\section{Conclusions}

(1) The present paper proposes a methodology to evaluate regional stability of red clay slope under different situations. Due to particularities of red clay, two typical failure modes exist in red clay slope. Underlying weak layers are frequently witnessed in integral failures due to reverse consolidation characteristics. On the contrary, heavy rainfall often causes superficial sliding for a considerable infiltration through developed microfractures.

(2) Improved three-dimensional Hovland model was used in the integral failure mode, while one-dimensional infiltration model and infinite slope model were applied in the planar sliding mode. Moreover, slip surface in integral sliding was considered as the lower part of an ellipsoid. The slip surface would be replaced by the interface of stratums or cracks if the ellipsoid locates beneath them. Infiltration depth and matric suction were taken into account in planar sliding, as well as the difference of sliding direction between each column and the entire sliding mass.

(3) The validity and practicability of this methodology has been partly verified. It is beneficial for narrowing critical ranges and centralizing preventive measures by overlaying various zonation maps according to different slope failure modes.

\section{Data Availability}

A part of the raw data cannot be shared at this time as the data also form part of an ongoing study.

\section{Conflicts of Interest}

The authors declare that there are no conflicts of interest regarding the publication of this paper.

\section{Acknowledgments}

This work was funded by the Natural Science Foundation, China (grant number: 51408059).

\section{References}

[1] W. Fang and G. L. Yang, "Research on the red clay deformation characteristics of Wuhan-Guangzhou passenger dedicated line (in Chinese)," Journal of Railway Engineering Society, vol. 25, no. 9, pp. 13-20, 2008.

[2] J. F. Lian and Q. Luo, "Failure modes and discriminating thresholds of soil subgrade slopes due to rain softening (in Chinese)," Chinese Journal of Rock Mechanics and Engineering, vol. 35, no. 8, pp. 1638-1647, 2016.

[3] A. Johari and A. M. Lari, "System probabilistic model of rock slope stability considering correlated failure modes," Computers and Geotechnics, vol. 81, pp. 26-38, 2017.

[4] E. C. Sung, "First-order reliability analysis of slope considering multiple failure modes," Engineering Geology, vol. 154, no. 3, pp. 98-105, 2013.
[5] D. R. Montgomery and W. E. Dietrich, "A physically based model for the topographic control on shallow landsliding," Water Resources Research, vol. 30, no. 4, pp. 1153-1171, 1994.

[6] R. T. Pack, D. G. Tarboton, and C. N. Goodwin, "The SINMAP approach to terrain stability mapping," in Proceedings of the Congress of the International Association of Engineering Geology, vol. 21-25, Vancouver, Canada, September 1998.

[7] L. Montrasio and R. Valentino, "A model for triggering mechanisms of shallow landslides," Natural Hazards and Earth System Sciences, vol. 8, no. 5, pp. 1149-1159, 2008.

[8] R. L. Baum, W. Z. Savage, and J. W. Godt, TRIGRS-A FORTRAN Program for Transient Rainfall Infiltration and Grid-Based Regional Slope Stability Analysis (Version 2.0), US Geological Survey Open-File Report, Denver, CO, USA, 2008.

[9] J. W. Godt, R. L. Baum, and W. Z. Savage, "Transient deterministic shallow landslide modeling: requirements for susceptibility and hazard assessments in a GIS framework," Engineering Geology, vol. 102, no. 3, pp. 214-226, 2008.

[10] Z. H. Liao and Y. Hong, "Evaluation of TRIGRS (transient rainfall infiltration and grid-based regional slope-stability analysis)'s predictive skill for hurricane-triggered landslides: a case study in Macon County, North Carolina," Natural Hazards, vol. 58, no. 1, pp. 325-339, 2011.

[11] Y. Tang, K.-l. Yin, L. Liu, L. Zhang, and X.-l. Fu, "Dynamic assessment of rainfall-induced shallow landslide hazard," Journal of Mountain Science, vol. 14, no. 7, pp. 1292-1302, 2017.

[12] M. Ciurleo, L. Cascini, and M. Calvello, "A comparison of statistical and deterministic methods for shallow landslide susceptibility zoning in clayey soils," Engineering Geology, vol. 223, no. 7, pp. 71-81, 2017.

[13] A. A. Raed, P. S. Ramesh, and A. Ahmad, "Seismic hazard assessment of Syria using seismicity, DEM, slope, active faults and GIS," Remote Sensing Applications, vol. 6, pp. 59-70, 2017.

[14] H.-J. Park, J.-H. Lee, K.-M. Kim, and J.-G. Um, "Assessment of rock slope stability using GIS-based probabilistic kinematic analysis," Engineering Geology, vol. 203, pp. 56-69, 2016.

[15] S. Sengupta, A. P. Krishna, and I. Roy, "Slope failure susceptibility zonation using integrated remote sensing and GIS techniques: a case study over Jhingurdah open pit coal mine, Singrauli coalfield, India," Journal of Earth System Science, vol. 127, no. 6, pp. 1-17, 2018.

[16] T. B. Hasan, A. Selcuk, and G. Zulfu, "Combination of discontinuity characteristics and GIS for regional assessment of natural rock slopes in a mountainous area (NE Turkey)," Catena, vol. 165, no. 6, pp. 487-502, 2018.

[17] B. Federici, R. Bovolenta, and R. Passalacqua, "From rainfall to slope instability: an automatic GIS procedure for susceptibility analyses over wide areas," Geomatics, Natural Hazards and Risk, vol. 6, no. 5-7, pp. 454-472, 2015.

[18] D. Laxmi, S. Rajeshwar, and D. Desh, "Comparative evaluation of GIS based landslide hazard zonation maps using different approaches," Journal of the Geological Society of India, vol. 93, no. 6, pp. 684-692, 2019.

[19] K. T. Naval and K. M. Anil, "Landslide vulnerability assessment in Gangotri valley glacier Himalaya through GIS and remote sensing techniques," Applied Water Science, vol. 9, no. 4, pp. 1-10, 2019.

[20] B. Amit, P. M. Bhabani, and D. Debasish, "Landslide hazard zonation mapping using multi-criteria analysis with the help of GIS techniques: a case study from Eastern Himalayas, Namchi, South Sikkim," Natural Hazards, vol. 96, no. 2, pp. 935-959, 2019. 
[21] F. Mirko, S. Doug, S. Nicola, and C. Fernando, "A new approach for defining Slope Mass Rating in heterogeneous sedimentary rocks using a combined remote sensing GIS approach," Bulletin of Engineering Geology and the Environment, vol. 78, no. 6, pp. 4253-4274, 2019.

[22] M. Ashraf and Z. Y. Zhao, "GIS-evaluation of two slopecalculation methods regarding their suitability in slope analysis using high-precision LiDAR digital elevation models," Hydrological Processes, vol. 26, no. 8, pp. 1119-1133, 2012.

[23] M. Martin, M. Ivan, and R. Mauro, "Spatially distributed three-dimensional slope stability modelling in a raster GIS," Geomorphology, vol. 206, no. 2, pp. 178-195, 2014.

[24] Z. Shuai and W. Fawu, "Three-dimensional seismic slope stability assessment with the application of Scoops3D and GIS: a case study in Atsuma, Hokkaido," Geoenvironmental Disasters, vol. 6, no. 1, pp. 1-14, 2019.

[25] Y. L. Liao and Q. T. Bi, "Discussion on pre-consolidation pressure of red clay (in Chinese)," Rock and Soil Mechanics, vol. 27, no. 11, pp. 1931-1934, 2006.

[26] L. R. Tan and L. W. Kong, "Fundamental property and microstructure model of red clay (in Chinese)," Chinese Journal of Geotechnical Engineering, vol. 23, no. 4, pp. 458-462, 2001.

[27] Z. H. Ren, The Research of Plant Protection on Red Clay Slope in Subtropical Rainy Area, Doctoral Dissertation, Lanzhou University, Lanzhou, China, 2016.

[28] H. J. Hovland, "Three-dimensional slope stability analysis method," Journal of Geotechnical Engineering Division, vol. 103, no. 9, pp. 971-986, 1977.

[29] M. D. James, "State of art: limit equilibrium and finite-element analysis of slopes," Journal of Geotechnical Engineering, vol. 22, no. 7, pp. 577-596, 1996.

[30] Z. P. Liu, J. Liu, and G. M. Du, "Three-dimensional slope stability analysis method based on Hovland improved model and constraint Delaunay TIN (in Chinese)," Chinese Journal of Rock Mechanics and Engineering, vol. 36, no. 1, pp. 32143223, 2017. 


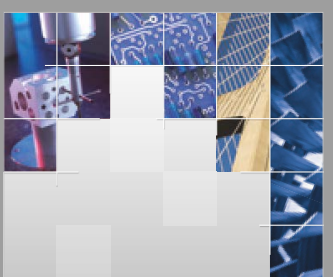

\section{Enfincering}
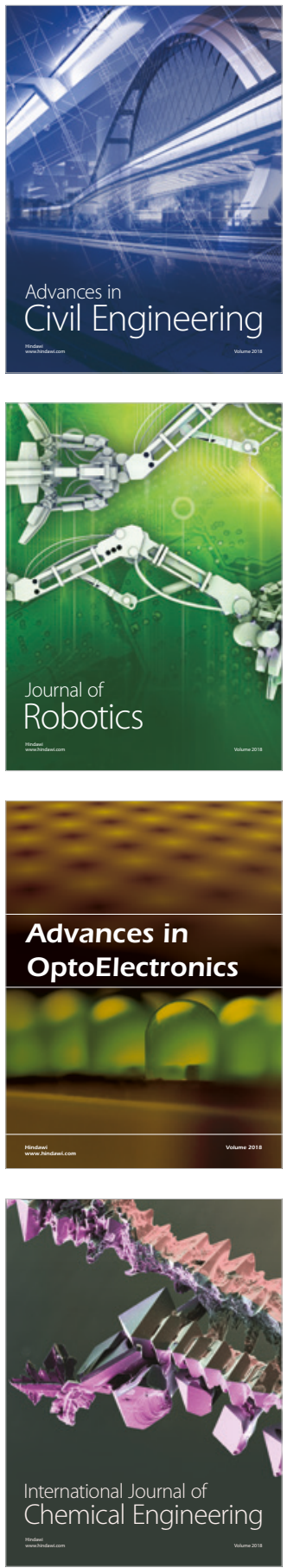

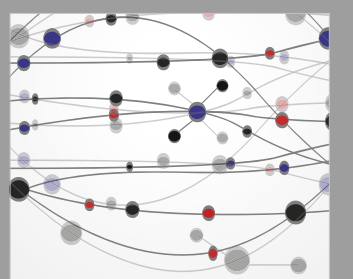

\section{Rotating \\ Machinery}

The Scientific World Journal

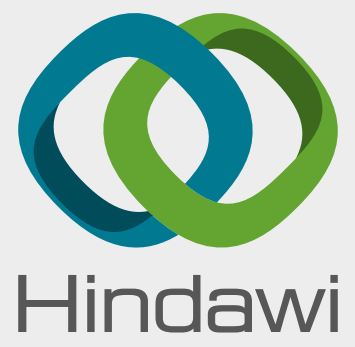

Submit your manuscripts at

www.hindawi.com
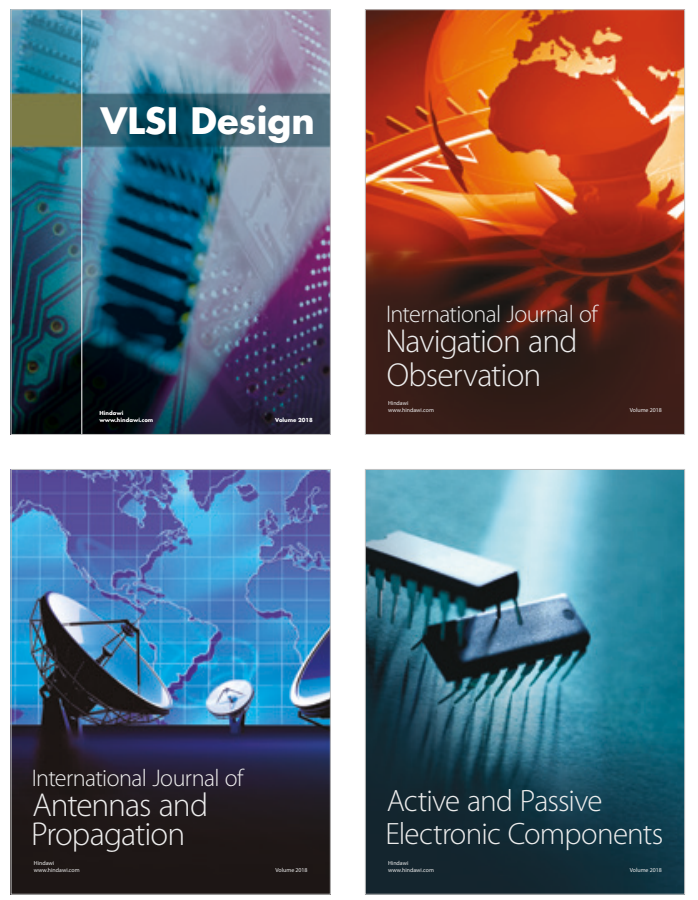
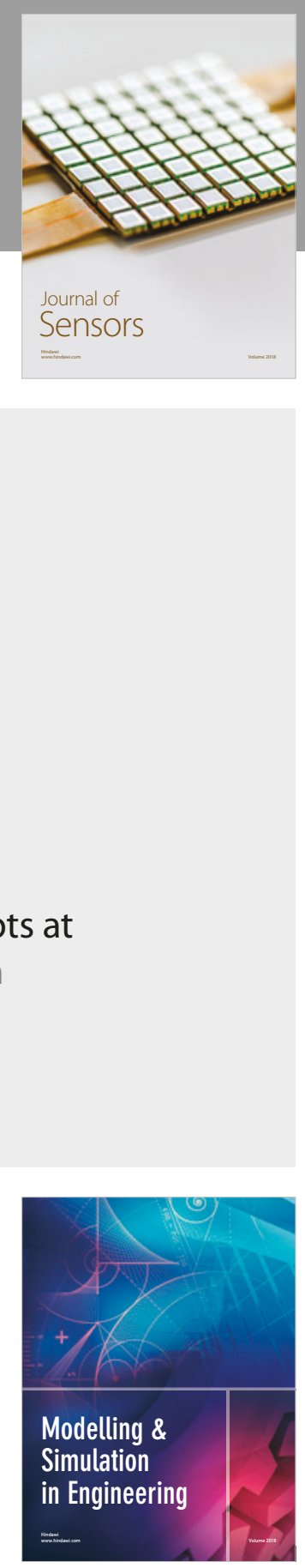

\section{Advances \\ Multimedia}
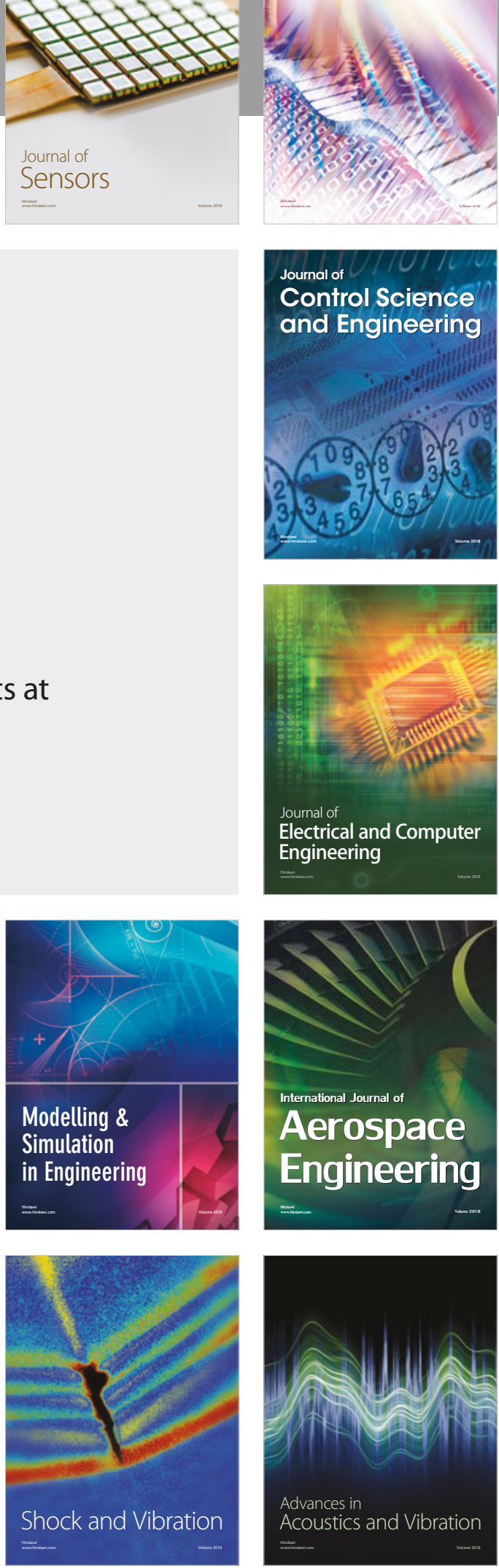